SOCRATES

\title{
SOCRATES 10 (synopsis of Cochrane reviews applicable to emergency services)
}

\author{
P Gilligan, J Jones, A Khan, D Hegarty, M Shepherd, G Lumsden, G Kitching, A Taylor, H Law, \\ J Brenchley
}

1:n this, the tenth article of the SOCRATES series, we present our synopses of reviews from the Cochrane Database of Systematic Reviews relating to gastroenterology and fluid management that the working party felt were of particular relevance to emergency medicine practitioners. The methods of our review and the rationale for the forming the SOCRATES working party are as have previously been published.

\section{HUMAN ALBUMIN SOLUTION FOR RESUSCITATION AND VOLUME EXPANSION IN CRITICALLY ILL PATIENTS \\ Background}

The objective of this review was to quantify the effect on mortality of human albumin and plasma protein fraction in the management of critically ill patients.

\section{Results}

A total of 30 randomised controlled trials were identified. In each of the patient categories the risk of death in the albumin treated group was higher than in the placebo group. There were 156 deaths among the 1419 patients. Overall the risk of death in patients treated with albumin is 6\% (95\% CI 3\% to $9 \%)$ higher than in patients not given albumin.

\section{SOCRATES says}

There is no evidence that albumin reduces mortality and a strong suggestion that it may increase the risk of death in patients with hypovolaemia, burns, and hypoproteinaemia. The role of human albumin in the management of the critically ill patient should be reviewed.

A The Albumin Reviewers (Alderson P, Bunn F, Lefebvre C, et al). Human albumin solution for resuscitation and volume expansion in critically ill patients (Cochrane Review). In: The Cochrane Library, Issue 1. Oxford: Update Software, 2001.

\section{HYPERTONIC VERSUS ISOTONIC CRYSTALLOID FOR FLUID RESUSCITATION IN CRITICALLY ILL PATIENTS Background}

Fluid resuscitation is the mainstay of medical management of haemorrhagic hypovolaemia. There is however uncertainty over the most appropriate fluid. It has been suggested that hypertonic solutions may be the fluid of choice as they have a greater ability to expand circulatory volume with only a rapid small volume infusion. It is also suggested they may be beneficial in head injured patients.

\section{Results}

Sixteen trials were found involving 837 patients. Four of the trials were in patients with burns, there were six trials in surgical patients, and six in trauma patients. Given the clinical heterogeneity of the different patient groups the Cochrane reviewers felt it would be inappropriate to pool them and so only the results of the subgroups were given. The pooled relative risk for death in trauma patients was 0.84 (95\% CI 0.61 to 1.16 ), for patients with burns 1.49 (95\% CI
0.56 to 3.95$)$, and for patients undergoing surgery 0.62 (95\% CI 0.08 to 4.57$)$.

\section{SOCRATES says}

At present there is insufficient evidence as to whether hypertonic crystalloid is better or worse than isotonic crystalloid; this does not rule out clinically important differences. Further research is required.

A Bunn F, Roberts I, Tasker R, et al. Hypertonic versus isotonic crystalloid for fluid resuscitation in critically ill patients (Cochrane Review). In: The Cochrane Library, Issue 4. Oxford: Update Software, 2000.

\section{COLLOIDS VERSUS CRYSTALLOIDS FOR FLUID RESUSCITATION IN CRITICALLY ILL PATIENTS Background}

For fluid resuscitation there are several options for fluid replacement. There has long been debate over which are the most effective. The main choices lie in crystalloid versus colloid (and which colloid). This review set out to assess the effects on mortality of colloids compared to crystalloids for fluid resuscitation in critically ill patients.

\section{Results}

Eighteen trials looked at albumin or plasma protein fraction. Seven trials looked at hydroxyethylstarch versus crystalloid, four trials compared modified gelatin and crystalloid, and eight trials looked at dextran versus crystalloid. Relatively few of the trials were randomised controlled trials and they differed in their regimes and allocation methods.

\section{SOCRATES says}

There is no evidence that colloids reduce the risk of death with burns, trauma, or following surgery. Colloids are considerably more expensive than crystalloids and therefore their continued use in this context is difficult to justify.

A Alderson P, Schierout G, Roberts I, et al. Colloids versus crystalloids for fluid resuscitation in critically ill patients (Cochrane Review). In: The Cochrane Library, Issue 1. Oxford: Update Software, 2001.

\section{SOMATOSTATIN OR OCTREOTIDE FOR ACUTE BLEEDING OESOPHAGEAL VARICES Background}

The hormone somatostatin and its derivative octreotide have been found to reduce portal blood flow or hepatic venous pressure gradient in experimental studies. This meta-analysis included all randomised trials comparing somatostatin or octreotide with placebo or no treatment in patients suspected of acute bleeding from oesophageal varices. The objectives of the study were to see if either of these drugs improved survival or reduced the need for blood transfusion in patients with suspected or confirmed bleeding oesophageal varices.

\section{Results}

Seven studies met the inclusion criteria for the meta-analysis, this included 820 patients. The drugs had no effect on 
survival with 91 dying in the experimental group versus 85 in the control group (odds ratio $1.04,95 \%$ CI 0.74 to 1.46 ). However, given the wide confidence interval a large placebo controlled trial is needed to ensure that a worthwhile effect on mortality has not been overlooked. There was an average of 1.2 units less blood used in the drug treated group. There were no significant differences in use of balloon tamponade, number of patients failing initial haemostasis, or number with rebleeding.

\section{SOCRATES says}

Treating bleeding in the oesophagus with these drugs has not been proven to reduce deaths, but it does appear to lessen the need for blood transfusions.

$\Delta$ Gotzsche PC. Somatostatin or octreotide for acute bleeding oesophageal varices (Cochrane Review). In: The Cochrane Library, Issue 4. Oxford: Update Software, 2000.

\section{CONCLUSION}

In this article the SOCRATES working party have summarised the reviews we felt were relevant to emergency practitioners in the Cochrane Database of Systematic Reviews relating to fluids and gastroenterology. In the next issue we will present our synopses of reviews relating to counselling, psychiatry, and psychology.

\section{ACKNOWLEDGEMENTS}

We would like to thank Dr Richard Hardern and the staff of the Postgraduate Medical Library at the General Infirmary at Leeds for their support and technical advice in the preparation of this paper.

\section{Authors' affiliations \\ P Gilligan, J Jones, A Khan, M Shepherd, G Lumsden, G Kitching, \\ A Taylor, H Law, J Brenchley, Specialist Registrars in Emergency \\ Medicine on The Yorkshire Rotation, UK \\ D Hegarty, General Practitioner, Leeds, UK \\ Funding: none. \\ Competing interests: none declared}

Correspondence to: Dr P Gilligan, 1 Far Moss, Alwoodley, Leeds LS17 7NU, UK; hegartydeirdre@ireland.com 